\title{
THE ELECTROCARDIOGRAM DURING ANGIOCARDIOGRAPHY
}

\author{
BY \\ GEOFFREY REYNOLDS \\ From the Cardiac Department, Guy's Hospital \\ Received June 24, 1952
}

It is often said that angiocardiography carries little risk, and series of more than a thousand injections without a death are on record (Sussman, 1948; Horger et al., 1951). During recent years, however, more than thirty deaths have been reported-the majority in children with cyanotic congenital heart disease. The exact cause of these deaths has still to be discovered.

When Mr. R. C. Brock began the surgical treatment of congenital heart disease at Guy's Hospital in 1947, it was found that angiocardiography formed an important part of the preliminary investigation of the patients. The risk of the procedure was soon confirmed and there were three deaths; the first two were reported by Campbell and Hills (1950), and all three (with the first of those described here) by Carnegie (1951). It was decided then to take electrocardiograms during the investigation in the hope of discovering the cause of such deaths and of providing a warning of impending trouble that might help to prevent them.

This paper analyses the first 75 consecutive electrocardiograms, taken on 73 patients, one of whom died. Records of two later patients who died are also described. 72 of these 75 patients had congenital heart lesions, the majority Fallot's tetralogy; all but 4 were cyanosed. Their ages ranged from 3 to 35 years.

The technique of the investigation used here has been described in detail by Carnegie (1951). General anæsthesia was given for 58 of the angiocardiographies, including all but two where the patient was under 14 years. Patients in the second half of the series received quinidine, 3-10 mg. by mouth, before the investigation, and procaine, 2-3 mg. per kilogram of body weight intravenously, during it in addition to routine premedication with sedatives. Diodone was the opaque medium used in every case, about $1.2 \mathrm{ml}$. of a 70 per cent solution per kilogram of body weight being injected into a peripheral vein.

The three standard electrocardiographic leads were taken before the injection, continuously for the first two or three minutes after it, and then intermittently as indicated.

\section{Electrocardiographic Changes}

The heart rate was usually between 100 and 150 a minute at the time of injection of the diodone. Characteristic changes followed this in 59 of the 75 cases-an initial slowing lasting twenty to thirty seconds, which may have been due to a direct effect of the diodone on the heart (Gordon et al., 1950), followed by an increase lasting for the next minute or two, and then a steady fall unless restlessness due to returning consciousness caused it to rise again.

Seventy-eight changes that were thought to be significant were recorded in $45(60 \%)$ of the 75 electrocardiograms in the series. These were divided into three groups: those that seemed to be due to injection of the diodone; those due to other factors concerned in the investigation, particularly the anæsthetic; and those probably not due to the procedure at all as they had been seen at other times (Table I). This grouping could, of course, only be approximate and there is 
no doubt that some of the changes that appeared to be due to the diodone may have been due to other causes and vice versa.

Changes were significantly more frequent among patients who were under anæsthesia $(69 \%)$ than among those who were not $(41 \%))^{*}$ This was largely due to changes that were thought, from the time they occurred, to be due directly to the anæsthetic.

Changes thought to be due to the diodone alone were also a little more frequent among patients under anæsthesia (52\%) than among those who were conscious $(41 \%)$; more frequent among the younger $(59 \%)$ than among the older patients $(39 \%)$; and significantly more frequent among those whose disability was above average $(65 \%)$ than among those in whom it was below this $(35 \%)$.*

TABLE I

Electrocardiographic Changes occurring duRINg 75 ANgIOCARDiographies

\begin{tabular}{|c|c|c|c|c|c|c|c|}
\hline & & & $\begin{array}{c}\text { Due } \\
\text { wholly to } \\
\text { diodone }\end{array}$ & $\begin{array}{l}\text { Due } \\
\text { partly to } \\
\text { diodone }\end{array}$ & $\begin{array}{l}\text { Due to } \\
\text { other } \\
\text { factors }\end{array}$ & $\begin{array}{l}\text { Occurring } \\
\text { normally }\end{array}$ & Total \\
\hline $\begin{array}{l}\text { Extrasystoles .. } \\
\text { Paroxysmal tachycardia } \\
\text { Changing pacemaker } \\
\text { Latent A-V block } \\
\text { Partial A-V block } \\
\text { Bundle branch block } \\
\text { S-T segment depression } \\
\text { S-T depression and/or }\end{array}$ & $\begin{array}{l}\ldots \\
\ldots \\
\ldots \\
\ldots \\
\ldots \\
\text { elevatio }\end{array}$ & $\begin{array}{l}\ldots \\
\cdots \\
\ldots \\
\ldots \\
\cdots \\
\ldots \\
\text { on }\end{array}$ & $\begin{array}{r}4 \\
2 \\
3 \\
10 \\
3 \\
6 \\
12 \\
5\end{array}$ & $\begin{array}{l}1 \\
0 \\
2 \\
1 \\
0 \\
3 \\
2 \\
3\end{array}$ & $\begin{array}{l}2 \\
0 \\
5 \\
1 \\
0 \\
2 \\
3 \\
2\end{array}$ & $\begin{array}{l}1 \\
0 \\
5 \\
0 \\
0 \\
0 \\
0 \\
0\end{array}$ & $\begin{array}{r}8 \\
2 \\
15 \\
12 \\
3 \\
11 \\
17 \\
10\end{array}$ \\
\hline Total & $\cdots$ & $\cdots$ & 45 & $\underbrace{12}$ & 15 & 6 & 78 \\
\hline Number of patients & $\cdots$ & . & $\underbrace{29}_{3}$ & 11 & 10 & 5 & 45 \\
\hline
\end{tabular}

The last was the most striking difference but was only present among the older patients (Table II). No significant factor was found among patients under ten years of age. There was no significant correlation between these changes and the degree of the patient's cyanosis.

TABLE II

Percentages of Patients showing Electrocardiographic Changes due to Diodone DIVIDED by AGE AND BY DEgREe OF DisAbILITY

\begin{tabular}{cccc} 
Age & & \multicolumn{2}{c}{ Disability } \\
below average & above average \\
$0-9$ years & & $56 \%(16)$ & $64 \%(22) \dagger$ \\
10 years and above & $\ldots$ & $15 \%(20)$ & $69 \%(16)^{*}$
\end{tabular}

Numbers of cases in each group are shown in brackets.

$\dagger$ Difference 8 per cent. Twice its standard error 32 per cent.

* Difference 54 per cent. Twice its standard error 28 per cent.

Ectopic Arrhythmias. Extrasystoles were recorded in only 8 cases; in 7 they were ventricular.

Paroxysmal ventricular tachycardia occurred as one of the multiple abnormalities that preceded ventricular fibrillation in the boy who died. Otherwise paroxysmal tachycardia occurred only once. This was in a patient who had no anæsthetic, and a nodal tachycardia appeared about three minutes after the diodone had been injected and lasted seven seconds.

No instance of auricular flutter or fibrillation was seen, but both flutter and fibrillation of the ventricle were recorded over a period of more than two hours in the boy who died.

* Difference more than twice its standard error. 
A change of pacemaker occurred in 15 cases.

In all, these arrhythmias were present in 18 cases. They were usually first seen before the injection of diodone. In six of them similar changes had been seen at other times; in seven they appeared to be wholly and in one partly due to the anæsthetic; and in two they seemed to be wholly and in three partly due to the diodone. In five cases such arrhythmias, present before the injection, disappeared a few seconds after it. They occurred less frequently in the patients given quinidine and intravenous procaine.

It is, thus, unusual for diodone to cause these arrhythmias, and it is as likely to stop them.

These findings contrast with those during angiocardiography where the injection is made through a catheter in the heart (Biorck et al., 1950) or during cardiac surgery (Campbell and Reynolds, 1952), when frequent arrhythmias are seen due to direct stimulation of the heart, in one by the catheter and in the other by the surgeon.

Conduction Defects. The P-R interval increased by 0.02-0.04 sec. in six cases, by $0.05-0.09$ sec. in three, and by $0 \cdot 16,0 \cdot 22$, and $0.29 \mathrm{sec}$. in a further three, in each of whom $2: 1$ heart block occurred.

Widening of the QRS complex by $0.02 \mathrm{sec}$. occurred in two cases, by $0.05-0.13 \mathrm{sec}$. in six, and there was at least a moderate increase in three others but its extent was hidden by $\mathrm{S}-\mathrm{T}$ segment changes.

In all, these defects were present in 19 cases. They usually started during the first minute after injection of the diodone. They appeared to be entirely due to the diodone in 12 , and partly due to it in another 5. However, all the severe and most of the moderate changes occurred in patients in the second half of the series who received quinidine and intravenous procaine.

$Q-T$ Interval. It was seldom possible to measure the $\mathrm{Q}-\mathrm{T}$ interval accurately due to overlapping of the $T$ and $P$ waves. It was not thought justifiable, therefore, to draw conclusions from the few where this could be done.

$S$-T Segment Deviation. S-T depression alone was present in 17 cases and elevation in another 10. It was $1 \mathrm{~mm}$. or less in thirteen, between 1 and $2 \mathrm{~mm}$. in ten, $3 \mathrm{~mm}$. in one, and $10 \mathrm{~mm}$. or more in three (Cases 4, 7, and 8; see later) where accurate measurement was not possible.

Twenty-four of the 27 patients were under anæsthesia, but the deviation appeared only after the injection in 18, usually during the first minute. In two of the three patients not under anæsthesia the deviation was first seen before the injection, though in both it increased afterwards.

Thus the diodone was responsible for these changes in most cases; but in some, another factor, which cannot always have been the anæsthetic, must have been at least partly the cause.

$T$ Waves. Changes in the $\mathrm{T}$ waves appeared to a greater or less extent almost constantly both before and after injection of the diodone. Both TI and TIII tended to be smaller than normal before the injection. After it TI became still smaller in almost all cases where a change occurred, but after a few minutes tended to increase again; while TIII tended to increase in size throughout this period. These changes usually bore no relation to other electrocardiographic or to clinical changes.

$P$ Waves. Changes in the $P$ waves were less than those in the $\mathrm{T}$ waves and appeared to be of no significance.

\section{Comparison with Clinical Changes}

Clinical cause for anxiety was not present as frequently as might have been expected from a study of the electrocardiographic changes that occurred during the investigations. There was serious anxiety over the condition of the patient during three of the 75 angiocardiograms in addition to the one who died; two other patients from a later series who died are included here for discussion.

The following are summaries of these 6 patients, 3 of whom died.

Case 1 (P086). This girl, 5 years old, had dextrocardia and a complicated heart lesion, which probably included pulmonary stenosis. Her disability was moderate, and her cyanosis moderate 
but increasing. Following injection of the diodone there was some increase in an S-T segment deviation that was normally present, but her clinical condition remained satisfactory until she collapsed in the ward half an hour after the injection. It was not possible to get a further electrocardiogram until she was recovering, and this continued to show only the slight increase in S-T deviation that had been present since the injection. More significant changes at the time of her collapse may have been missed.

Case 2 (P087), Fig. 1. This boy, 5 years old, had Fallot's tetralogy. His disability and cyanosis were moderate, and he had been having spontaneous attacks of dyspnœea and cyanosis. Under anæsthesia, before injection of the diodone, there was some difficulty in getting him to breathe; his cardiogram at this time showed a partial bundle branch block, which was still present at the

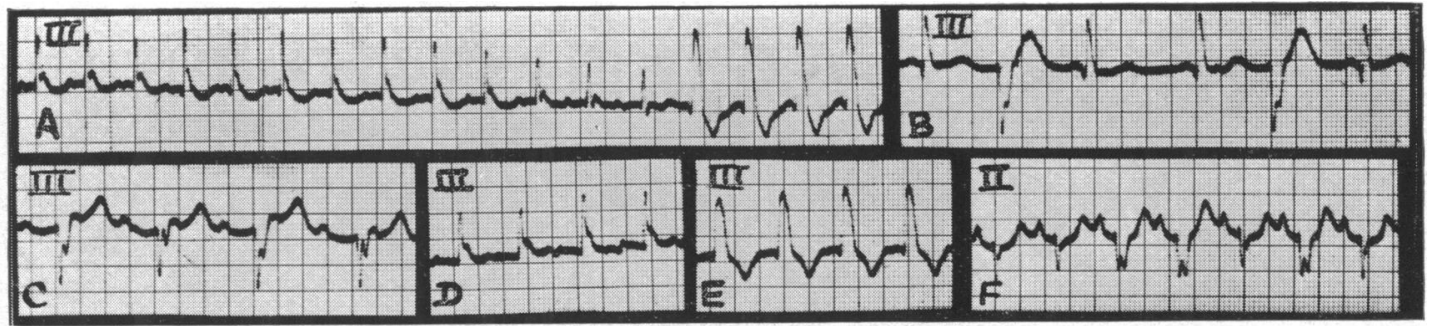

Fig. 1.-Case 2, lead III. (A) At the time of injection of the diodone, showing momentary disappearance of a bundle branch block and its reappearance in a more complete form at four and a half seconds after the start of the injection. (B) One minute after the injection, showing less bundle branch block, but now a partial A-V block and ventricular extrasystoles. (C) At seven minutes, showing $2: 1 \mathrm{~A}-\mathrm{V}$ block and a considerable change of axis. (D) At twenty minutes, still showing some bundle branch, but no A-V block. (E) At the time of his collapse at twenty-one minutes, showing a more severe bundle branch block. (F) Lead II three hours later, showing the bundle branch block becoming intermittent.

time of the injection. Immediately after this a series of abnormalities started due to depression of conduction-prolongation of the P-R interval, partial A-V block, and bundle branch blockand later frequent ventricular extrasystoles; but collapse only occurred twenty-one minutes after the injection, concurrently with the most complete bundle branch block he had yet shown. Clinical and cardiographic recovery started two hours later. A grossly distended stomach may have been an important factor here in causing cardiac embarrassment.

Case 3 (P130). This girl, 4 years old, had a single ventricle and pulmonary stenosis. Her disability and cyanosis were moderate. Following injection of the diodone both blood pressure and cardiographic changes were slight until she collapsed six and a half minutes later; simultaneously a partial A-V block developed and lasted for more than twenty minutes. Consciousness then soon returned. Excess bronchial secretions may have been a factor in this case.

Case 4 (O029), Fig. 2. This boy, aged 11 years, had Fallot's tetralogy. His disability was moderate and cyanosis slight, but he had been having attacks of unconsciousness. An ectopic rhythm was present for a few seconds immediately after injection of the diodone. Half a minute after the injection elevation of S-TIII began, with depression of S-TI, and was followed by widening of the QRS complexes. One and a half minutes later the patient collapsed, the previous cardiographic changes becoming more severe. An increasing arrhythmia led to ventricular tachycardia, flutter, and fibrillation, and the patient died.

Case 5 (O034), Fig. 3. This boy, aged 6 years, had pulmonary atresia. His disability and cyanosis were moderate. No significant change immediately followed the injection. Nodal rhythm appeared between one and a half and two minutes and was present most of the time until, at four minutes, there was a simultaneous fall in blood pressure and appearance of bundle branch block, with a partial A-V block for a short time at first. The blood pressure rapidly became unrecordable. Later multiple ventricular extrasystoles appeared, at first in short bursts of paroxysmal 


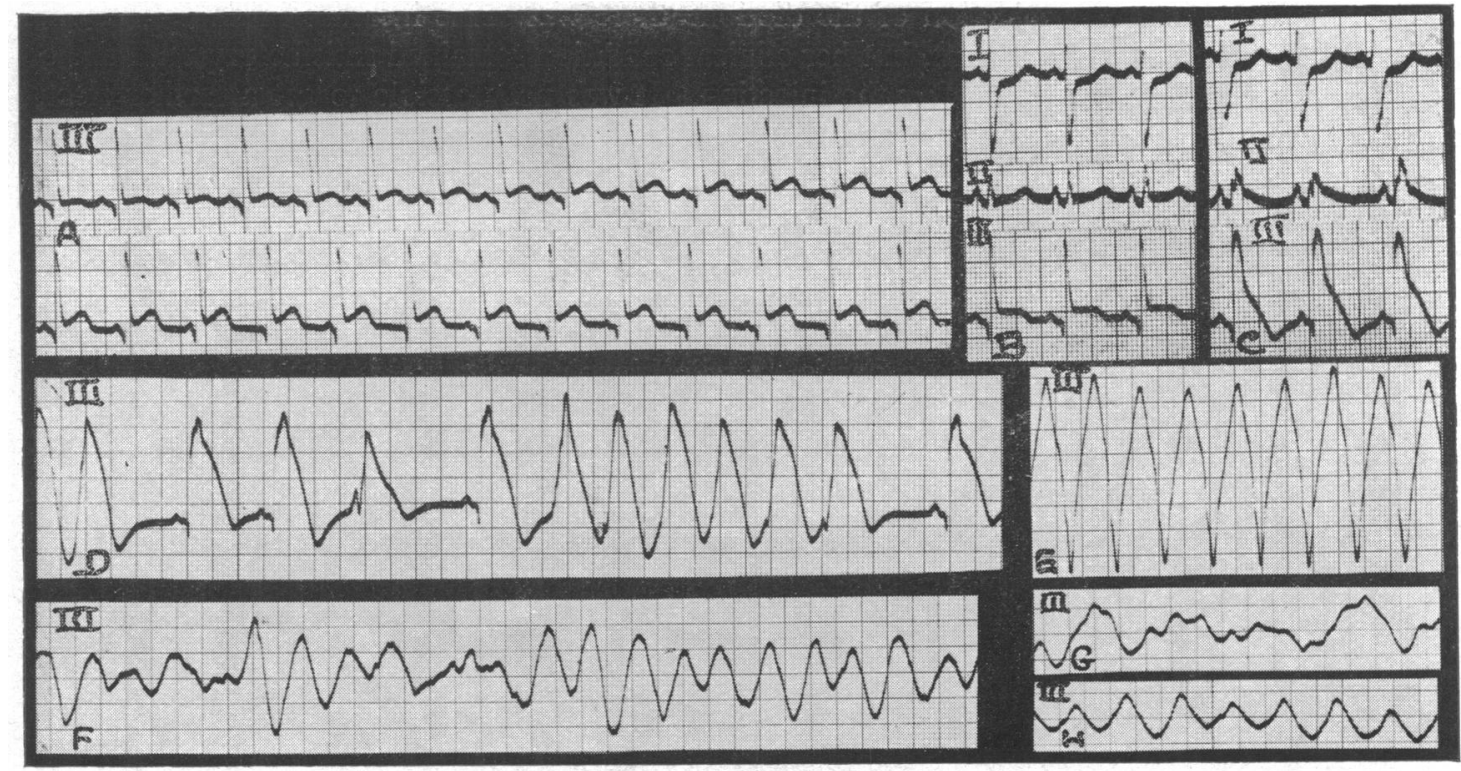

FIG. 2.-Case 4. (A) Lead III between 33 and 47 seconds after injection of the diodone, showing commencing elevation of the S-T segment. (B) and (C) Standard leads at one and a half and two minutes after the injection, showing depression of S-TI, increasing elevation of S-TIII and widening of the QRS complexes. (D)-(F) Lead III at two and a half, six, and eight minutes after the injection, showing severe bundle branch block and S-T elevation, ventricular tachycardia, flutter, and fibrillation. (G) and (H) Lead III two hours later, showing ventricular flutter and fibrillation still present, with a suggestion of auricular activity in (G).

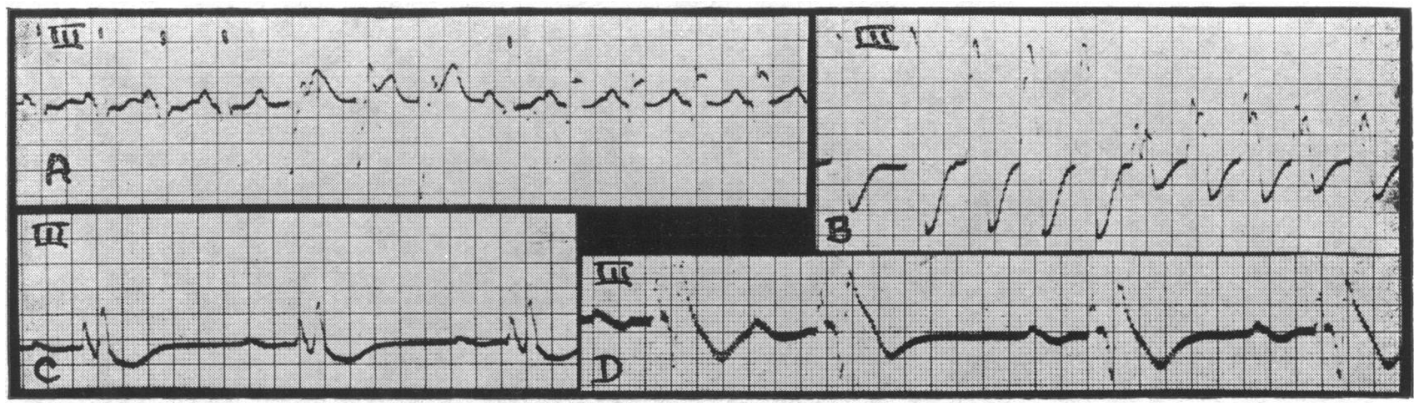

FIG. 3.-Case 5, lead III. (A) At four minutes after injection of the diodone, showing the onset of a changing bundle branch block. (B) At twenty-four minutes, showing a ventricular tachycardia that was present almost continuously from twelve and a half minutes after the injection until cardiac massage was abandoned. (C) and (D) Many minutes after cardiac massage had been abandoned and the patient was dead, showing recognizable auricular and ventricular complexes.

tachycardia, and then gradually disappeared leaving a slow irregular sinus rhythm, which was increased by methedrine until a partial $\mathrm{A}-\mathrm{V}$ block slowed the ventricular rate once more. An irregular ventricular tachycardia appeared at twelve and a half minutes and persisted almost without a break up to the time that cardiac massage was abandoned.

Case 6 (P077), Fig. 4. This girl, aged 5 years, had transposition of the great vessels and pulmonary stenosis. Her disability and cyanosis were moderate, but she had had three attacks of unconsciousness. Her electrocardiogram was continuously abnormal from the time of the initial record shortly after the induction of anæsthesia. An ectopic and changing pacemaker was present most of the time before injection of the diodone, and frequently there was a variable A-V and an alternating bundle branch block. Sinus rhythm was re-established for the first minute after the 


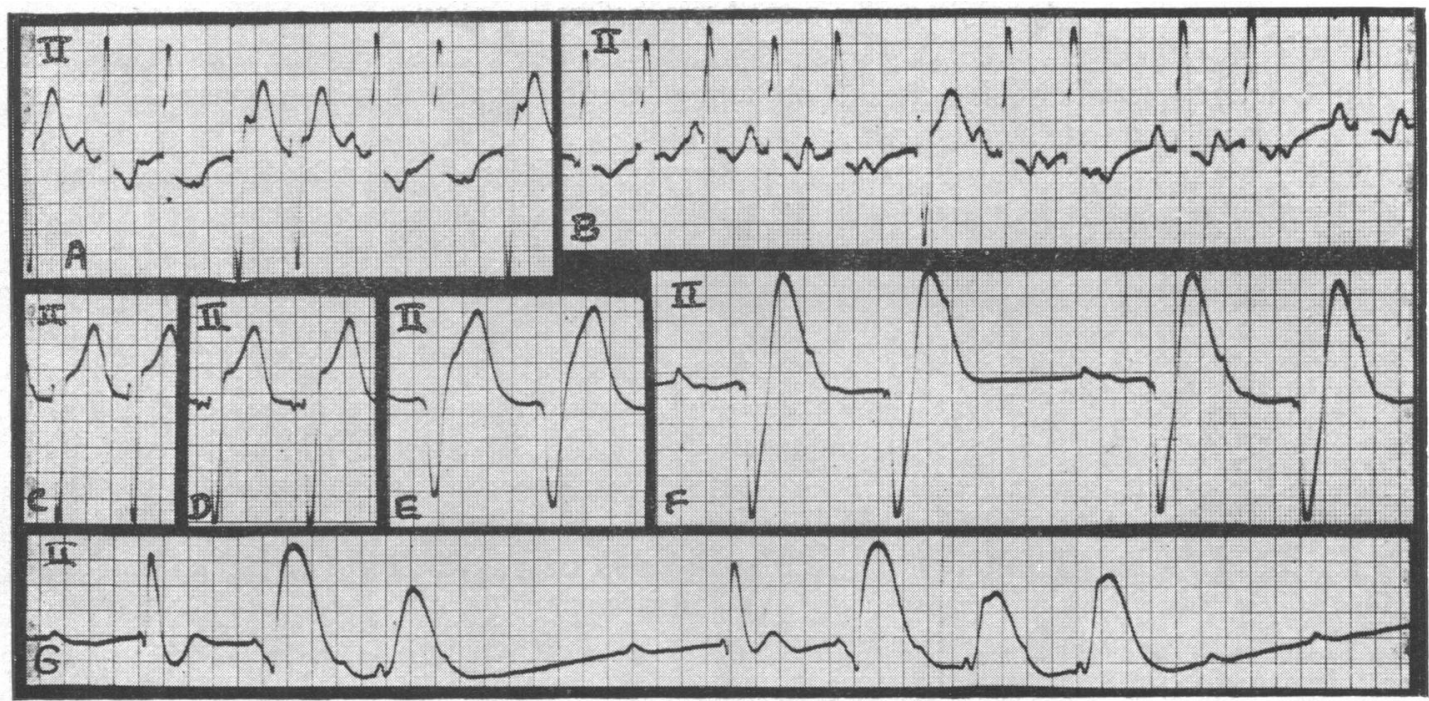

Fig. 4.-Case 6, lead II. (A) Before injection of the diodone, showing a changing pacemaker, $6: 5 \mathrm{~A}-\mathrm{V}$ block, and changing bundle branch block. (B) Between seven and ten seconds after the injection, showing the return of the sinus pacemaker. (C) and (D) At two and six minutes, showing slowing of a regular ectopic rhythm. (E) At the time of her collapse at eight minutes, showing a slow ventricular rhythm with greatly widened complexes. (F) At fifteen minutes, showing an auricular rhythm again, with a long P-R interval, $4: 3 \mathrm{~A}-\mathrm{V}$ block, and even wider ventricular complexes. (G) The final, grossly abnormal tracing after the patient was dead.

injection, but the partial A-V and bundle branch blocks remained until the former disappeared at two minutes: after this a regular ectpoic rhythm and bundle branch block persisted with a slowly decreasing rate until six minutes. At eight minutes the patient, whose condition had been satisfactory up to this time, collapsed, her cardiogram showing a slow ventricular rhythm. Thereafter an auricular rhythm returned intermittently with much delay in A-V and intraventricular conduction, while the rhythm became more irregular and the complexes more abnormal; and this continued long after the patient's death.

Three other patients showed severe electrocardiographic changes. One (Case 7) developed a severe S-T deviation and bundle branch block like that in Case 4 who died, but in this case it disappeared in little more than a minute (Fig. 5A). In another (Case 8) similar changes occurred

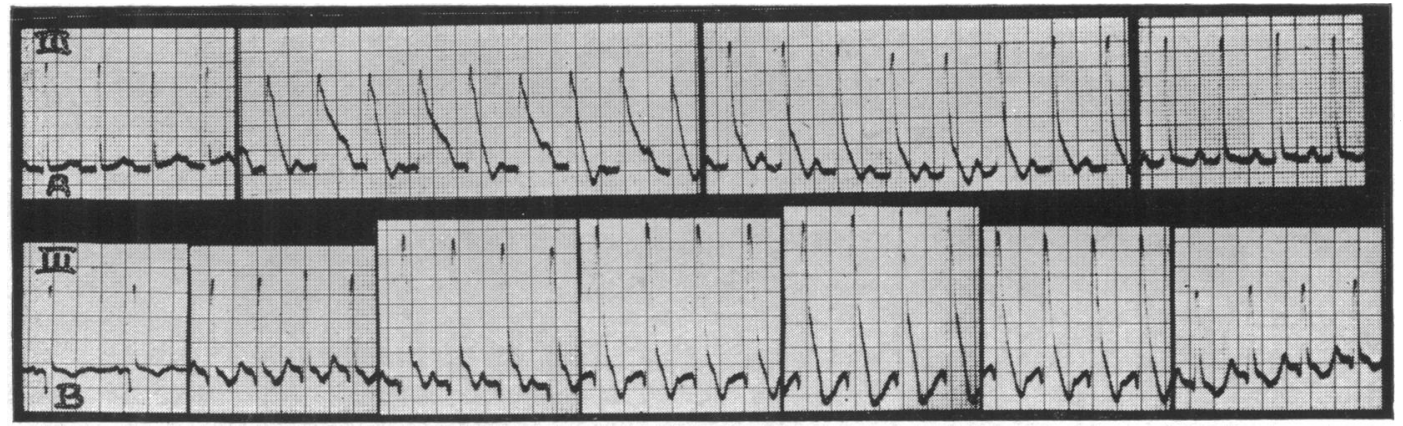

FIG. 5.-(A) Case 7, lead III at 40, 60, 90, and 120 seconds after injection of the diodone, showing a transient but severe bundle branch block and elevation of the S-T segment, and an odd, alternating obliquity of the latter. (B) Case 8, lead III, normally and at intervals of a few minutes while the patient was under anæsthesia before injection of the diodone, showing the appearance and disappearance of a bundle branch block and elevation of the S-T segment. 
and resolved spontaneously while under anæsthesia before injection of the diodone without any clinical cause for anxiety (Fig. 5B). The third patient (Case 9) showed signs of a severe depression of both A-V and intraventricular conduction, and gave some anxiety due to a severe fall of blood pressure after injection of the diodone.

A fall in blood pressure was first reported to occur in this investigation by Robb and Steinberg in 1939 and shown graphically by Howarth (1950). It was an almost constant finding during the second half of the series in which this observation was made, and took place within a minute of the injection. The degree of the fall varied greatly, from a few millimetres to an unrecordable pressure. The systolic pressure fell more than $50 \mathrm{~mm}$. in 5 of the 21 patients for whom figures are available, and in these the electrocardiographic changes were, on the average, twice as severe as in those in whom it fell less than this. These changes were of depressed conduction in four and S-T deviation in the fifth. They had been present in one before the injection and increased immediately after it; in the others they started between twenty and sixty seconds after the injection. Only in one of these patients did the clinical condition give rise to anxiety in any other way.

Thus a severe early fall of blood pressure was always associated with a very abnormal electrocardiogram, but usually without any subsequent cause for anxiety; while such a fall and immediate change in the electrocardiogram were not constant in those patients who later collapsed. Pressures were taken in four patients who collapsed: one had no early fall and one had only a slight fall, and neither of these showed early electrocardiographic changes; while two had severe early falls accompanied by considerable electrocardiographic changes.

One other patient caused some anxiety by persistent vomiting, which started about twenty minutes after the injection, and by a delay of about an hour in returning to consciousness. His cardiogram following the injection showed a moderate degree of S-T depression but this lasted only a few minutes.

The early abnormalities seen in patients whose clinical condition gave rise to anxiety were mainly those of a depressed conduction and to a lesser extent of S-T deviation. However, the initial change in all three patients who died was the appearance of an ectopic pacemaker; although in one it was accompanied by abnormalities that were more certainly pathological and in the other two it disappeared before more serious disturbances occurred. As this arrhythmia was seen for the first time after the injection in only one other case, it may have a greater significance in these circumstances than it usually has.

\section{Cause of Clinical Changes}

The diodone must be mainly responsible for the danger of this investigation, though other factors certainly add to the danger. The effects of the diodone may be exerted in several ways.

Peripheral vasodilatation probably causes the fall in blood pressure (Howarth, 1950) and unpleasant symptoms that immediately follow the injection, since the initial central effect of the diodone is to increase the amplitude of pulsation, at least of the isolated heart (Heathcote and Gardner, 1945; Weatherall, 1942).

Increase in vascular permeability leading to a direct toxic action on the tissues may cause its later effects. Such lesions have been shown in the brain after intra-carotid injection of diodone by Broman and Olsson (1949), and electro-encephalographic abnormalities were noted by Mannheimer et al. (1951) after intravenous injection in a number of cases where an overriding aorta was present.

Alternatively vascular spasm may be responsible; this has been shown to occur after intraarterial injection (van der Linden, 1942), but there is no evidence that it follows intravenous injection. However, Mikulicich (1951) took electrocardiograms on rabbits during injection of foreign proteins to which they had been sensitized and recorded abnormalities that were remarkably similar to ours during angiocardiography. He believes these changes to be due to spasm of the coronary vessels and pulmonary arterioles, and permeability changes in the tissues. Diodone may, perhaps, produce similar effects in a sensitized subject. Certainly the risk of angiocardiography 
in patients with an allergic tendency is generally agreed, and Sussman and Grishman (1947) even consider it inadvisable when there is a history of allergy among relations.

The bulk of the injection, its hypertonicity, and other non-specific effects are unlikely to be of great importance since they do not differ from those of other contrast media, and yet these substances produce different effects (Weatherall, 1942).

Where severe electrocardiographic changes precede the patient's collapse they suggest that the effect is directly on the myocardium or, in view of the frequent occurrence of pulmonary symptoms and pulmonary œedema, on the lungs through anoxæmia and consequent myocardial ischæmia. Where severe changes occur only at the time of the collapse a peripheral failure seems more likely, and this may have a direct peripheral, a reflex, or a cerebral origin. The essential lesion may vary from case to case or it may always be peripheral but sometimes accentuated by a preceding cardiac embarrassment.

It is usually considered that anæsthesia increases the risk of the investigation and should be avoided if possible (Carnegie, 1951), though Mannheimer et al. (1951) advocate it as reducing allergic and toxic reactions. Our results provide little evidence that it is an added risk, for the ectopic arrhythmias (probably due to cyclopropane) that were its common effect before the injection seemed of little consequence, and it did not appear to accentuate the more serious changes that followed the injection. But there can be no doubt of its danger if it allows anoxia to develop, and this may have been the cause of the more significant changes that occasionally preceded the injection, including those seen in Case 8.

Quinidine and intravenous procaine lessen ectopic arrhythmias, but these are less frequent after injection of the diodone than depression of conduction; this tends to be accentuated by these drugs, probably more so in a damaged heart (Uhley and Wilburne, 1948; Long et al., 1949; Graubard et al., 1948). They should, therefore, be given with caution.

The absence of any correlation between the electrocardiographic changes and the degree of cyanosis indicates that the presence of a dextroposed aorta or the degree to which it is overriding is unlikely to be a significant influence on the risk of the investigation. On the other hand there was a significant correlation with the degree of disability. The disability of those with pulmonary stenosis, who formed the majority of our patients, is due to an inability to increase their pulmonary blood flow, and this may be the most important condition predisposing to the appearance of electrocardiographic changes during angiocardiography and to the cardiac embarrassment that these changes often indicate.

\section{The Value of Continuous Electrocardiography}

Electrocardiography is especially helpful during angiocardiography before the injection of diodone has been given, when it may reveal changes-particularly those due to depressed conduction-that after the injection are likely to increase and to be followed by collapse and even death of the patient. On three occasions since this was recognized conduction defects have been present before the injection, and for this reason the injection was abandoned.

After the injection has been given the electrocardiographic changes, especially those that first appear or increase in severity more than two minutes after the injection, may provide a warning that all is not well, and so allow earlier efforts to be made to maintain or restore the blood pressure or resuscitate the patient; but changes may only appear at the time of the collapse.

\section{SUMMARY}

Electrocardiograms taken during 75 angiocardiograms are described. Most of the patients had cyanotic congenital heart disease. Sixty per cent showed significant changes. These were most frequent in the younger, and least in the older and less disabled patients.

Ectopic arrhythmias were seen in about a quarter of the patients. They usually appeared to be due to the anæsthetic and were stopped on several occasions by the injection of diodone. Defects 
of conduction were seen in about the same number but appeared to be due to the diodone, though they may have been accentuated by the quinidine and intravenous procaine given to reduce ectopic arrhythmias. S-T deviation was seen in about a third of the patients; it was usually due to diodone, sometimes to the anæsthetic, and occasionally to more obscure factors.

A fall in blood pressure was almost constant immediately after injection of the diodone, and simultaneous cardiographic changes were related to it in degree. Later a general collapse, bearing no close relation to the initial effects, might occur suddenly between two and thirty minutes after the injection, and might or might not be preceded by an abnormal electrocardiogram.

The lesion causing the collapse may be in the heart or lungs or brain, or may be peripheral. It may result from vascular spasm, perhaps as an allergic reaction, or from a direct toxic action on the parenchyma.

Electrocardiograms should be taken during this investigation in cases of cyanotic congenital heart disease. When abnormalities due to depressed conduction or S-T deviation are present and are not obviously due to an anoxia that can be quickly rectified, the investigation should be abandoned.

I wish to express my sincere thanks to Dr. Maurice Campbell for his help in the interpretation of the electrocardiograms and advice on the preparation of this paper. I also gratefully acknowledge the help I received from Mr. Ian Hill and Mr. Lawrence Whytehead, who performed the angiocardiograms, and from Mr. F. H. Muir, Senior Technician in the Cardiac Department, Guy's Hospital.

This paper is a summary of a thesis submitted and accepted for the degree of D.M. (Oxon), and I wish to thank the Regius Professor of Medicine for permission to publish it.

\section{REFERENCES}

Broman, T., and Olsson, O. (1949). Acta radiol., 31, 321.

Biorck, G., Sylvan, T., and Lindbloom-Tillman, G. (1950). Acta cardiol., 5, 509.

Campbell, M., and Hills, T. H. (1950). Brit. Heart J., 12, 65.

, and Reynolds, G. (1952). Cardiologia, (in the press).

Carnegie, D. M. (1951). Brit. med. J., 1, 1230.

Gordon, A. J., Brahms, S. A., Megibow, S., and Sussman, M. L. (1950). Amer. J. Roentgenol., $64,819$.

Graubard, D. J., Kovacs, J., and Ritter, H. H. (1948). Ann. intern. Med., 28, 1106.

Heathcote, R. St. A., and Gardner, R. A. (1933). Brit. J. Radiol., 6, 304.

Horger, E. L., Dotter, C. T., and Steinberg, I. (1951). Amer. Heart J., 41, 651.

Howarth, S. (1950). Brit. med. J., 2, 1090.

van der Linden, P. C. (1942). Arch. int. Pharmacodyn., 67, 14.

Long, J. H., Oppenheimer, M. J., Wester, M. R., and Durant, T. M. (1949). Anesthesiology, $10,406$.

Mannheimer, E., Landtman, B., and Melin, K. A. (1951). Cardiologia, 19, 337.

Mikulicich, G. (1951). Allergy, 22, 249.

Robb, G. P., and Steinberg, I. (1939). Amer. J. Roentgenol., 42, 14.

Sussman, M. L. (1948). Surg. Gynec. Obstet., 87, 349.

$\longrightarrow$, and Grishman, A. (1947), in Advances in internal Medicine, Interscience, New York, $2,102$.

Uhley, M. H., and Wilburne, M. (1948). Amer. Heart J., 36, 576.

Weatherall, M. (1942). Brit. J. Radiol., 15, 129. 